University of Nebraska - Lincoln

DigitalCommons@University of Nebraska - Lincoln

Robert G. Fuller Publications and Presentations Research Papers in Physics and Astronomy

November 1974

\title{
Repeatable Testing-A Tool for Learning Physics
}

David E. Golden

Robert Fuller

rfuller@neb.rr.com

Donald D. Jensen

University of Nebraska - Lincoln

Follow this and additional works at: https://digitalcommons.unl.edu/physicsfuller

Part of the Physics Commons

Golden, David E.; Fuller, Robert; and Jensen, Donald D., "Repeatable Testing-A Tool for Learning Physics" (1974). Robert G. Fuller Publications and Presentations. 6.

https://digitalcommons.unl.edu/physicsfuller/6

This Article is brought to you for free and open access by the Research Papers in Physics and Astronomy at DigitalCommons@University of Nebraska - Lincoln. It has been accepted for inclusion in Robert G. Fuller Publications and Presentations by an authorized administrator of DigitalCommons@University of Nebraska - Lincoln. 


\section{Repeatable Testing-A Tool for Learning Physics}

\author{
DAVID E. GOLDEN \\ ROBERT G. FULLER \\ Department of Physics \\ DONALD D. JENSEN \\ Department of Psychology \\ University of Nebraska \\ Lincoln, Nebraska 68508
}

(Received 4 February 1974)

The performance of college students in introductory physics courses has been studied using conventional examination procedures as a measure of content mastery. Retesting over the same physics content using repeatable equivalent examinations results in a significant increase in the students mastery of physics. Students greatly preferred this type of examination procedure.

\section{INTRODUCTION}

Physics courses have traditionally used onechance-only examinations as a probe to tell the professor how much physics each student has learned, with the result that physics examinations have been a common cause of anxiety among undergraduates.

Repeatable equivalent examinations, on the other hand, offer an alternative testing procedure which underscores material not mastered on the first examination and then allows remedial study of this material for the next examination. Furthermore, the thought that it will be possible to have another try at the examination greatly decreases the anxiety associated with examinations.

While repeatable examinations are routinely used in Keller-plan courses, ${ }^{1}$ this article shows that they can be used in the usual lecture demonstration format as well. ${ }^{2}$

\section{RATIONALE}

The technique of giving repeatable equivalent examinations, of allowing more than one chance to demonstrate competence with the material, has several desirable effects. It allows the instructor to satisfy his conflict between his demand of high student performance and his commitment to the transmittal of important ideas and information. The instructor can expect high performance on examinations because students can be expected to increase their knowledge of physics through a series of examinations. If the student's pace is insufficient to obtain a satisfying grade on the first try, he can increase his pace in order to succeed on the next. Work rather than worry can be expected from the student. ${ }^{3}$ While the intensity of concentration is still heightened by the examination, the anxiety of complete failure is removed since the examination may be repeated.

The grading in the course can reflect the mastery of the material by the student rather than his position on some "normal distribution." The use of a normal distribution curve to determine grades supposes that every group of students who take a course is equivalent to every group who have taken the course. This is not necessarily true. A significant effect of absolute grading is that it decreases competition between students. With absolute grading, students can study together and help each other without fear of jeopardizing their own grades. Furthermore, the mastery concept of grading offers the student the opportunity to have a feeling of accomplishment and achievement independent of what all the other students are doing.

\section{PROCEDURES AND RESULTS}

We have now used repeatable testing in three different physics courses using several different formats. In all cases the students have shown a significant improvement in their mastery of the physics content through repeatable tests. 


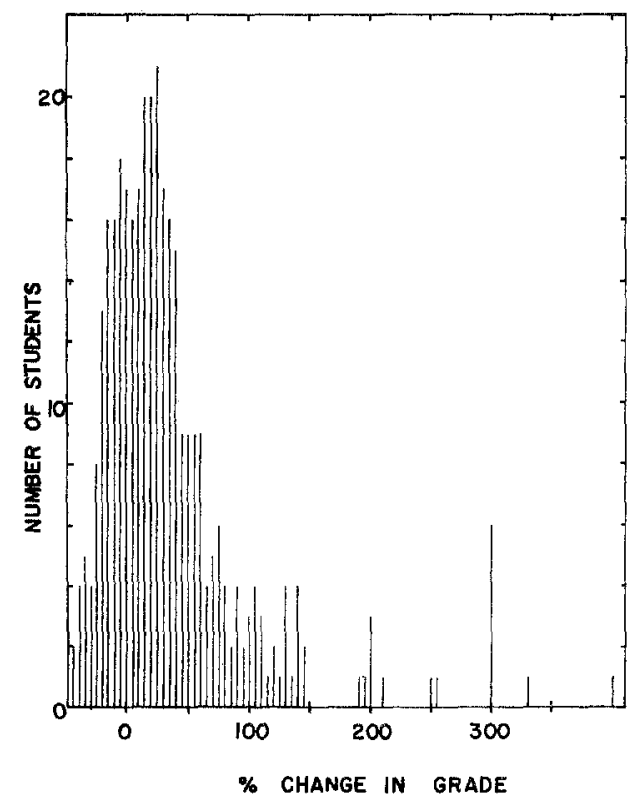

FIG. 1. Distribution of grade changes between one examination and a repeated equivalent examination.

One of our courses was a Keller-plan style precalculus course in which three different, but approximately equivalent, two-hour, midterm examinations were given. The individual test questions were written to evaluate the student knowledge of a set of learning objectives, and three different tests were written covering the same set of learning objectives. The students were permitted to take any or all of the midterm exams, which were offered at two week intervals. The students with satisfactory grades were discouraged from taking further tests by using the policy of averaging the test scores if the scores decreased, but giving the highest test score if the test scores increased.

One of our courses was a traditional lecture course in general physics for engineering students. In this course, two of four one-hour exams given during the semester were offered twice and the student was given the highest score that he obtained on either exam. Each form of the repeatable exam consisted of four numerical problems over three chapters of the textbook.

Our third course was a traditional lecture demonstration course in pre-calculus physics for pre-medical students, and each of two one-hour exams was offered twice. Each form of the hour exam consisted of ten short-answer discussion questions and two numerical problems. The numerical problems on different forms of the test were written to test the same problem solving skills. Both of the examinations representing the same material were made up at the same time and the order of giving the examinations was decided by chance.

The results of all of these uses of repeatable testing are shown together on Fig. 1 in the form of a histogram. Not included on the graph are two grades greater than $+400 \%$ and one grade less than $-50 \%$. The distribution is skewed in the direction of increase in grades. This is an indication that most students took advantage of the opportunity to repeat the examination over the same material by better preparing themselves for the second examination. The median grade change was $+20 \%$ while the average grade change was $+40 \%$ in repeating the examination. Furthermore, the attitudes of the students about the exams improved remarkably. No longer were examination discussion periods highlighted by arguments over test scoring details. Rather the students were eager to learn how to do the physics correctly so that they might be able to score higher on the next examination. In course evaluation questionnaires the students were overwhelmingly favorable toward the idea of repeatable testing. In one section in the first semester of physics for engineering and science students, $95 \%$ of the students wrote unsolicited comments in favor of the idea of repeatable testing on the back of the course evaluation forms. At the end of the semester the students in the pre-calculus course were given a course evaluation questionnaire: $13 \%$ of the students indicated they would have liked no midterm examination, $6 \%$ would have liked one midterm examination for everyone, and the remaining $81 \%$ of the students preferred repeatable testing.

\section{CONCLUSIONS}

'The use of repeatable testing in physics offers the instructor a way to improve the learning environment in his class. With repeatable testing, 
students increase their knowledge of physics and are more positive in attitude towards the subject matter. Most important, perhaps, repeatable testing can change the social environment surrounding instruction, changing students from competitors for a limited number of high grades, to potential study partners, and changing instructors from punitive task-masters, who apportion grades, to teachers, who set clear goals and seek to help all their students attain those goals.

1 F. S. Keller, J. Appl. Behav. Anal. 1, 78 (1968).

${ }^{2}$ R. R. Lewis, Jr., Phys. Teach. 12, 21 (1974).

${ }^{3}$ D. D. Jensen, Educ. Tech. 28 (1973). 